\section{AAAJ \\ 34,8}

\section{4}

\title{
Who cares? These are (not) my problems!
}

Brewing Colombian coffee,

A speedy click on my Twitter feed.

Curious me! Why so busy? More notifications than usual.

The $\mathrm{R}$ rate and the number of deaths are falling.

Great! Pleased that the vaccine is working.

What does Boris say about ending lockdown?

When would schools and pubs open, Boris?

Who cares? These are not my problems.

Moving on quickly, slurping and sipping coffee.

Myanmar coup - three killed, hundreds arrested,

Businesses closed, workers on strike.

People are organizing even in the pandemic

Against the Junta to emancipate Suu Kyi! Great!

I still wonder, where were they

During the ethnic cleansing of thousands of Rohingya?

Perhaps her freedom is more important

Than the lives of a million Rohingya.

But then I am neither Rohingya nor Burmese.

Who cares? These are not my problems.

Wearing a sky-blue cotton gown made in Bangladesh,

Holding a cup of tea produced in Sri Lanka,

My wife joins me, "Good morning.

You look serious. What are you reading?"

UK seeks new UN resolution on

The human rights violations in Sri Lanka, I said.

Military and rebels are accused of killing

100,000 civilians, mostly minorities.

Another 150,000 trapped because of civil war.

"The whole world is doomed. What is wrong with people?"

My wife said with a heavy heart. Cannot agree more!

But hey, "Don't you get stressed!

We are not Sinhalese or Tamil," I tried to console.

Who cares! These are not our problems.

Finishing her Sri Lankan tea,

She prepared for her Zoom meeting on

Workers' well-being. 
I continued swiping the Twitter feed.

What are my colleagues posting?

A few articles are on forced labour,

And Modern Slavery in Supply Chain. Excellent!

Some webinars on too.

Aren't they resilient, and not giving up?

Encouraged me to finish my revisions,

Addressing eight pages of comments

In six months, with 8,000 words

That must be achieved. No alternatives.

Two papers at least in ABS $3 *$ are needed,

Four out of five SAMT [1] score demanded.

External funding would be appreciated.

Like my colleagues at Leicester,

Failing would make me unneeded.

I care because these are my problems!

Do we have time to worry about others?

Would easing lockdown, a falling $\mathrm{R}$ rate,

Or recovering economy

Give us any comfort, I asked?

"Of course! What could be happier than

Going back to our normal lives," she replied.

Thinking of people in Myanmar or Sri Lanka

Would make any differences? "No.

But it would endanger your peace,

Perhaps cost your job too." I nod. True!

Who cares? These are not my problems!

I have mountains to climb.

Are you a capitalist? Or a neoliberalist?

My inner soul asks.

I do not know. I am confused!

Maybe both, maybe neither.

Definitely, no time to be a socialist,

Whatever the ambivalence. I chose to ignore it,

Put my iPhone aside, finish my Columbian coffee,

Prepare for my Zoom class to dwell on

'Accounting for Human Rights'.

I do care!

Md Shoaib Ahmed

Essex Business School, Faculty of Social Sciences, University of Essex, Colchester, UK

\section{Note}

1. Students Assessment of Modules and Teaching.

\footnotetext{
About the authors

Md Shoaib Ahmed is Lecturer in the Department of Accounting, Essex Business School, University of Essex. His current research focuses on corruption, gender marginalization, modern slavery, oppression, workplace incivilities and their association with accounting practices in the global supply chain.
} 